ГORIGINAL ARTICLE-

Volume 11 Issue 42019

DOI: 10.21315/eimj2019.11.4.2

ARTICLE INFO

Submitted: 26-08-2019

Accepted: 18-09-2019

Online: 31-12-2019

\section{The Students' Perceptions and Attitudes towards Blended Learning among Undergraduate Students in Kuala Lumpur}

\author{
Ahsha Vaksalla', Nur Zakiah Mohd Saat' ${ }^{2}$ Ismarulyusda Ishak ${ }^{3}$, \\ Siti Aishah Hanawi ${ }^{4}$, Hazilah Mohd Amin ${ }^{4}$, Siti Salwana Kamsan', \\ Nur Natasha Zulkifli', Dayang Nor Suzliana John² \\ ${ }^{1}$ School of Healthcare Sciences, Faculty of Health Sciences, \\ Universiti Kebangsaan Malaysia, Kuala Lumpur, MALAYSIA \\ ${ }^{2}$ Programme of Biomedical Science, School of Community Health, \\ Faculty of Health Sciences, Universiti Kebangsaan Malaysia, \\ Kuala Lumpur, MALAYSIA \\ ${ }^{3}$ Programme of Biomedical Science, School of Diagnostic E Applied \\ Health Science, Faculty of Health Sciences, Universiti Kebangsaan \\ Malaysia, Kuala Lumpur, MALAYSIA \\ ${ }^{4}$ Research Center for Software Technology and Management, \\ Faculty of Information Science E Technology, \\ Universiti Kebangsaan Malaysia, Selangor, MALAYSIA
}

To cite this article: Vaksalla A, Mohd Saat NZ, Ishak I, Hanawi SA, Mohd Amin H, Kamsan SS, Zulkifli NN, John DNS. The students' perceptions and attitudes towards blended learning among undergraduate students in Kuala Lumpur. Education in Medicine Journal. 2019;11(4):19-28. https://doi.org/10.21315/eimj2019.11.4.2

To link to this article: https://doi.org/10.21315/eimj2019.11.4.2

\begin{abstract}
Blended learning resulted in improving learning and student satisfaction. A cross-sectional study was done to determine the perception and attitude of undergraduates among gender, years of study and departments. There are three domain that has been considered which is perception, the concepts of blended learning and the negative impression are explored in this study. A total of 126 students from Year 1 and Year 2 were recruited as respondents from two departments in the university in Kuala Lumpur. Students had high preferences to perception and concepts of blended learning. In terms of perception, there was a significant difference in the departments to blended learning among biomedical and nutrition students. There was a significant difference for domain negative expression and concept of blended learning between department according to the result of multivariate test.
\end{abstract}

Keywords: blended learning, perception, undergraduate, Kuala Lumpur

Dr. Nur Zakiah Mohd Saat, Programme of Biomedical Science, School of Community Health, Faculty of Health Sciences, Universiti Kebangsaan Malaysia, Jalan Raja Muda Abdul Aziz, 50300 Kuala Lumpur, Malaysia | E-mail: nurm1605@gmail.com

\section{INTRODUCTION}

Blended learning is a combination of conventional learning and e-learning using web and internet applications (1). Blended learning can also refer to a combination of several methods in devices such as smartphones. Popular applications such as Kahoot! and web EdTech tools such as Blendspace can be used to enhance the 
learning process. There are many differences between blended learning and conventional methods; one of the main differences is the use of a variety of media within the learning system. The advantages of the new learning process to the learners are that blended learning gives them an alternative way to learn and they can decide on how and where to get the information regarding the topics provided by teachers and lecturers (2).

The use of social media such as Facebook in academic platforms has been popular since the year 2000. This innovation continues as many research studies have been designed to implement blended learning in order to improve the teaching and learning process thereby increasing teacher and student satisfaction. In addition, blended learning has been reported to facilitate and increase motivation for the student to explore knowledge whilst at the same time improving their soft skills such as communication and peer interaction. Many researchers have studied the effectiveness of the blended learning approach and identified many challenges, especially the need for educators to become up-to-date with the technologies involved. In Malaysia, technology gives encouragement and motivation to teaching and learning activities, thereby attracting increasing attention from both students and professionals, especially in higher education institutions (3).

The application of the blended learning process among the students has resulted in an increase in the percentage of students passing examinations (4-5). Blended learning has become part of the teaching materials and learning experiences that are increasingly important to both instructors and students (3). Blended learning is a good exercise to encourage students to use technology such as the internet instead of lecture notes (6). Moreover, it has positive impacts by increasing their creativity and developing previously little-used skills such as adding videos to their presentations. In our study, blended learning is referred to Ifolio, Kahoot!, YouTube and Facebook.
Furthermore, studies have shown that combining blended learning with conventional teaching, such as e-learning with face-to-face lectures, has enhanced the teaching and learning process. Nowadays, more researchers are interested in studying and examining the various factors that influence students towards using the e-learning system. Previous studies reported that using blended learning by including "gamification" has made study more fun and interesting (7). Implementing blended learning involves combining several sources of teaching materials and methods, so that the student can apply them in their learning to improve academic performance compared to traditional methods. In the perceptions of the users, blended learning is easy to use on computers, smartphones and tablets. However, much depends on the information and technology skills of the user and they may require hands-on support from their friends and instructors if they are not confident users of e-learning systems. Previous studies have shown that e-learning systems can lead to success in students' academic performance and to increased instructor and student satisfaction (8). Many higher education institutions worldwide are gradually introducing blended learning to enhance teaching and learning. The previous study in Europe indicates that most universities have a great interest in applying Massive Open Online Courses (MOOC) in their curricula (9).

The students' perception and attitude towards blended learning is important to determine the acceptance of these new methods. Students and teachers work together to enhance the quality of learning and teaching. This study is to determine the perceptions and attitudes of undergraduate students towards blended learning. Therefore, the research question for this study is: Is there any difference of perception, attitude and negative impression between biomedical sciences students and nutrition students, according to year of study, gender and department? 


\section{METHODOLOGY}

\section{Participants}

The participants consist of 126 students from two different university undergraduate departments in Kuala Lumpur, Malaysia. The selection of students was made using stratified sampling methods. Firstly, the size of the required sample was calculated. Then it was stratified according to the departments involved, nutrition and biomedical sciences. Furthermore, the proportion of the total students from each department was calculated. Using this proportion, the total sample for each department was calculated. Then, the proportion of students according to department was used to determine the sample size for Years 1 and 2. Usually, the proportion of students per year of study is almost the same. The exclusion criteria for the sample was, if the student was absent, deferred or involved in practical work.

\section{Instrument}

The survey questionnaire was adapted and modified from a previous study by Ja'ashan (10). The researcher developed the questionnaire by critically reviewing the literature related to blended learning. The validity and reliability of the questionnaire have been tested systematically. The questionnaire consists of 36 items which are categorised into three domains: students' perceptions of, and attitudes to, blended learning; negative impressions of blended learning; and the concepts of blended learning. The scoring of this questionnaire uses a 5-point Likert scale scored from 1 to 5; strongly disagree, disagree, undecided, agree, and strongly agree. However, for negative questions the scoring was the opposite of the positive questions.

\section{Analysis}

The data were analysed using descriptive analysis to determine the level of perceptions of, and attitudes to, blended learning among Years 1 and 2 from the nutrition and biomedical science departments. The normality test was conducted using the Kolmogorov-Smirnov test, the Skewness ratio and Boxplot. The data was normally distributed therefore the independent $t$-test was used to examine the perceptions of, and attitudes to, blended learning for the selected groups of students.

\section{RESULTS}

Table 1 showed the total number of students was 126 from the two departments. There were 64 Year 1 students and 62 Year 2 students. Of these, 86 students were from Biomedical Science Department and 40 students were from nutrition department. According to gender, there were 24 male students and 102 female students. While for race, there were 92 Malay, 22 Chinese and 14 Indian students.

The descriptive results from Table 2 indicated that the total overall mean for the student's perception and attitudes is 47.73, the negative impression is 36.103 and the concept in blended learning is 45.198. The data was been categorised to "not preferable", "moderate preferable" and "preferable" using percentile. The total mean score for student perceptions and attitudes, and the concept of blended learning had score more than 45 , therefore both sections were in the category of preferable level. This indicated that on average student appreciate and prefer the blended learning as a medium of giving lecture and assignment instead of face-toface learning.

According to Table 3, the mean score of perception and attitude for nutrition and biomedical sciences department were 45.42 and 44.38 respectively. Meanwhile, according to the year of study, the mean score of perception and attitude for Year 1 and Year 2 were 47.91 and 46.98 . This indicated that the students from the biomedical sciences department and Year 1 preferred blended learning compared to the 
Table 1: Background of the subjects $(n=126)$

\begin{tabular}{lcc}
\hline Background & $\mathbf{n}$ & Percentage (\%) \\
\hline $\begin{array}{l}\text { Department } \\
\text { Biomedical Science }\end{array}$ & 86 & 68.25 \\
$\quad$ Nutrition & 40 & 31.75 \\
Year of study & & \\
1 & 64 & 50.79 \\
2 & 62 & 49.21 \\
Race & & \\
$\quad$ Malay & 92 & 73.02 \\
$\quad$ Chinese & 22 & 17.46 \\
Indian & 12 & 9.52 \\
Gender & & \\
$\quad$ Male & 24 & 19.05 \\
$\quad$ Female & 102 & 80.95 \\
\hline
\end{tabular}

Table 2: Mean score of perception and attitude, negative impression, and concept of blended learning $(n=126)$

\begin{tabular}{lcc}
\hline Variables & Mean & SD \\
\hline Perception and attitude & 47.730 & 6.382 \\
Negative impression & 36.103 & 6.985 \\
Concept & 45.198 & 6.370 \\
\hline
\end{tabular}

student from the nutrition department and Year 2 student.

Based on the descriptive results, the highest mean score was for Q1 which is the web for e-learning in university system is present logically and the lowest mean score was Q9 which is blended learning task is clear. This means the students agreed that the e-learning system in the university is useful for them to upload assignments and to download lecture notes. However, the instructions given by the lecturers through the e-learning system were not clear and this gives problems to them to understand what they need to do for the assignments.

Next, descriptive result also shows the results for Domain 2, regarding the negative impression. The scoring in the questionnaire indicate that the highest score represents the lowest negative impression. According to the descriptive result, the highest mean score represents for Q18, "the blended learning was a waste of time". Meaning that, on average student disagree that blended learning is a wasting time. Meanwhile, Q13 scored the lowest mean which indicated that on average the student agreed on slow internet connectivity is the main problem of blended learning.

Results also shows for Domain 3, which is the concept of blended learning. The highest mean score was for Q25, "students agreed that the online videos allow us to listen to a native speaker". This indicated that on average students agreed that the usage of online video helps them to understand the topic of the lecture much clearer. The lowest score was for Q27, "blended learning more convenient than face-toface". This showed that on average the students disagree that blended learning is more convenient compared to face-to-face learning. This may be due to the curriculum 
for Year 1 and Year 2 which is more on learning the basic concept compare to applications. Therefore, it was challenging for them to understand lectures using blended learning or many media compared to conventional method of learning.

Independent $t$-test was used to analysed on a sample of 126 students to examine the differences in the year of study and department on the student's perception and attitude of blended learning. The results were presented in Table 3 for domain perception and attitude by department with nutrition ( $\mathrm{n}=40)$ and biomedical science ( $\mathrm{n}=86$ ). The $t$-test showed statistically significant difference, with the nutrition department (mean $=45.42$, standard deviation $=6.07)$, reporting perception and attitude at -2.21 (the difference between the two means). The minus sign indicates that nutrition department students had lower mean score than biomedical science students (mean $=48.38$, standard deviation $=7.37), t(124)=-2.21$, $p=0.029$. However, there was no significant mean difference of concept and negative impression on blended learning between department $(p>0.05)$.

According to the year of study for perception and attitude (refer Table 4), the number of participants for Year 1 students $(\mathrm{n}=64)$ and Year 2 students $(\mathrm{n}=62)$. The $t$-test was not statistically significant, with the Year 1 students (mean $=47.91$, standard deviation $=5.49$ ) reporting perception and attitude at 0.922 (the difference between the two means), the positive sign indicates that Year 1 students had higher mean score than Year 2 students $($ mean $=46.98$, standard deviation $=8.45)$, $t(124)=0.730, p=0.467$. Meanwhile for other variables concept and negative impression showed no significant mean difference $(p>0.05)$

Table 3: Independent $t$-test between department on concept, perception and negative impression of blended learning

\begin{tabular}{lllllcc}
\hline Variables of blended learning & Department & $\mathbf{n}$ & Mean & Sd & $\boldsymbol{t}$ & $\boldsymbol{p}$-value \\
\hline Concept & Nutrition & 40 & 44.43 & 7.18 & -1.05 & 0.296 \\
& Biomedical Sc. & 86 & 45.73 & 6.125 & & \\
Perception and attitude & Nutrition & 40 & 45.42 & 6.07 & -2.21 & $0.03^{*}$ \\
& Biomedical Sc. & 86 & 48.38 & 7.37 & & \\
Negative impression & Nutrition & 40 & 36.18 & 5.99 & 0.028 & 0.978 \\
& Biomedical Sc. & 86 & 36.14 & 7.42 & & \\
\hline
\end{tabular}

Note: ${ }^{*} p<0.05$

Table 4: Independent $t$-test between year of study on concept, perception and negative impression of blended learning

\begin{tabular}{lcccccc}
\hline Variables of blended learning & Year & $\mathbf{n}$ & Mean & Sd & $\boldsymbol{t}$ & $\boldsymbol{p}$-value \\
\hline Concept & 1 & 64 & 45.87 & 5.93 & 0.982 & 0.328 \\
& 2 & 62 & 44.74 & 6.99 & & \\
Perception and attitude & 1 & 64 & 47.91 & 5.49 & 0.730 & 0.467 \\
& 2 & 62 & 46.98 & 8.45 & & \\
Negative impression & 1 & 64 & 35.61 & 6.37 & -0.879 & 0.381 \\
& 2 & 62 & 36.69 & 7.55 & & \\
\hline
\end{tabular}


A two-way ANOVA was done on a sample of 126 students to examine the interaction of gender, year of study and department on perception and attitude of blended learning. Based on Table 5, the main effects which is department $(\mathrm{F}=4.792, \mathrm{df}=1$, $p=0.03$ ) was significant. Meanwhile the main effect year of study $(F=0.913$, $\mathrm{df}=1, p=0.33$ ) was not statistically significant. The test statistic also showed no significant interaction between year of study and department on perception and attitude of blended learning, $F=2.749$, $p=0.1$. Partial eta square $\left(\eta^{2}=0.022\right)$ indicates that the interaction effects between the variables is small. Hence, the interaction of year of study and department on perception and attitude of blended learning among undergraduate students learning is weak. From the profile plot it indicated that the perception on blended learning was higher among Year 1 student compared to Year 2 student from nutrition department. Whereas, the perception on blended learning was higher among Year 2 compared to Year 1 student from biomedical science department.

Another interesting result showed that for domain concept of blended learning, the main effects which is department and interaction effect showed significant mean difference. Based on Table 5, the main effects showed $(\mathrm{F}=4.617, \mathrm{df}=1$, $p=0.033)$ and interaction effect gender $x$ department $(\mathrm{F}=4.509, \mathrm{df}=1, p=0.036)$. Partial eta square was 0.035 indicating the interaction effect is small. Meanwhile for perception, both of the main effects gender and department showed significant mean difference as shown in Table 5. However, the interaction effect gender $\times$ department was not significant $(\mathrm{F}=0.460, \mathrm{df}=1$, $p=0.499$ )

\section{DISCUSSION}

In this study there were three domain and the highest total score was moderately. Students had low levels of negative impression towards blended learning. This finding is parallel to a study in Greece, which indicated that there was no significant difference of behaviour among students before and after implementing blended learning (11). However, the finding was in contrast with a study in Spain, where the students showed positive effects towards blended learning and increased their performance in class (12). The concept of blended learning in this study was mostly on how the blended learning will benefit them. The results indicated that it was moderately preferred by the student. This was parallel with other study in Saudi, where the student agreed that blended learning will make them easier to communicate with instructor through the internet, short message service (SMS), Facebook and

Table 5: Test of between subject effects

\begin{tabular}{llccc}
\hline Variables of blended learning & Background & F & df & $\boldsymbol{p}$-value \\
\hline Concept & Gender & 0.018 & 1 & 0.894 \\
& Dept & 4.617 & 1 & $0.033^{*}$ \\
& Gender $\times$ Dept & 4.509 & 1 & $0.036^{*}$ \\
Perception and attitude & Gender & 4.481 & 1 & $0.036^{*}$ \\
& Dept & 4.792 & 1 & $0.030^{*}$ \\
Negative impression & Gender $\times$ Dept & 0.460 & 1 & 0.499 \\
& Year & 0.913 & 1 & 0.33 \\
& Dept & 8.503 & 1 & $0.001^{*}$ \\
& Year $\times$ Dept & 2.749 & 1 & 0.100 \\
\hline
\end{tabular}

Note: Dept: Department; ${ }^{*} p<0.05$ 


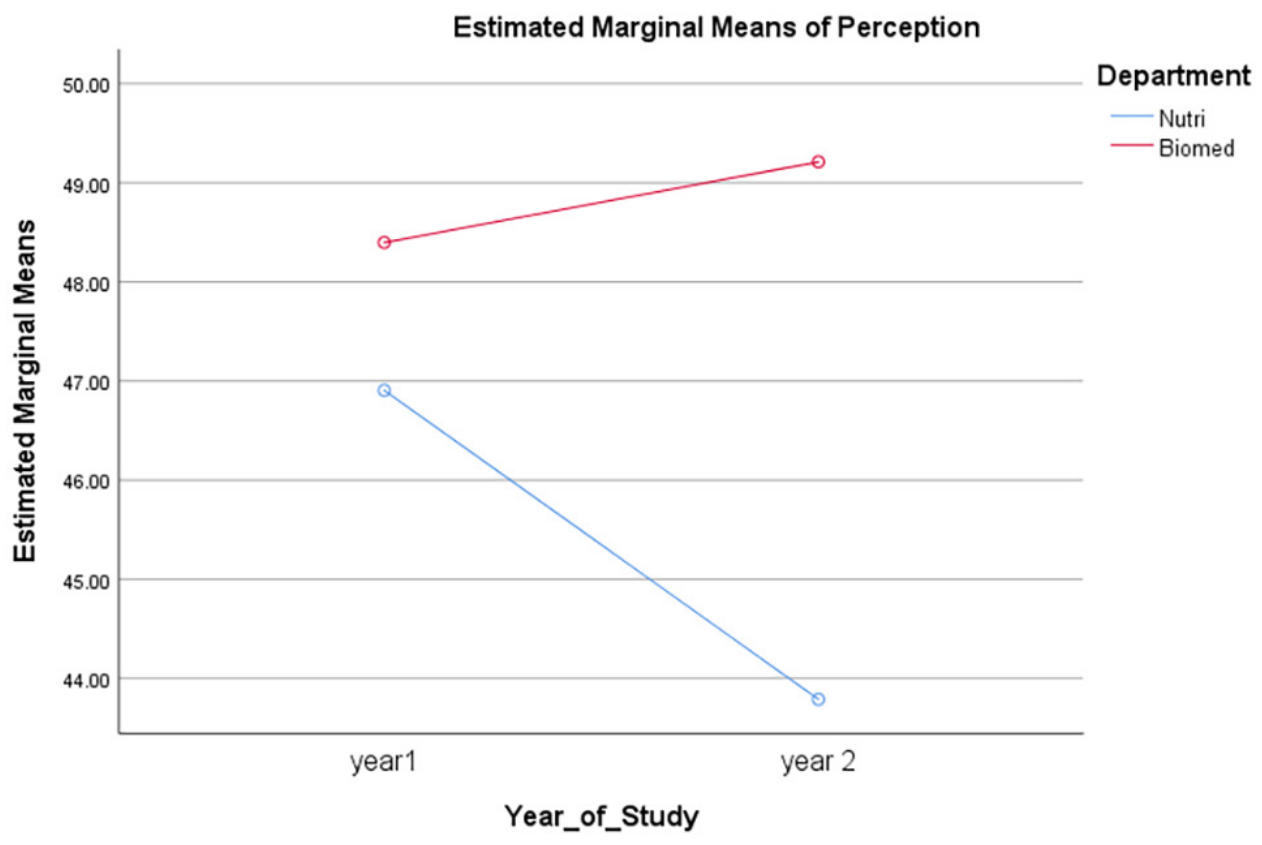

Figure 1: The profile plots of perception of blended learning between year of study and department.

others. By using blended learning, students can watch the online video many times in order to understand the lecture or the topics (13). Furthermore, study also showed that engineering and health science student prefers the use of Facebook, YouTube and blogs as this will motivate them to understand the lecture better (14-15).

The levels of students' perceptions and attitudes towards blended learning were discussed by item. Students agreed that Ifolio, Kahoot!, YouTube and Facebook are presented logically. Students perceived that the blended learning activities give them a chance to read. Students stated that the blended learning courses are interesting and useful. Students agreed that the concepts in blended learning, such as the online videos, allowed them to listen to native speakers (16-17). However, in the students' perceptions, the instructions in the assignments are not clear. This is parallel with previous study in Malaysia, as the students found it difficult to understand the content due to the use of English language jargon and terminologies (18).
Personal devices assisted student learning and the layout was stated to be attractive. Students found that blended learning is more convenient than face-to-face learning, especially with devices such as tablets and smartphones (19). The negative impression among students stated that blended learning can be difficult for them to do, especially when there are problems with internet connections. Sometimes the technology makes the students feel socially isolated and wasted their time as they need to spend more time on the internet. The main challenge for blended learning is slow internet connections. Therefore, universities, colleges and schools should have a good internet connection to implement blended learning (20). Besides that, for group work in blended learning the cooperation of group members is important for completing the task. For example, the facilitator needs to give a reminder to all group members to do some of the task.

There were many challenges faced by the university in adopting blended learning. A study in Saudi Arabia showed that it required a significant amount of time to 
change the culture of a university which has been used to conventional methods of learning. Furthermore, the instructor of the course must decide the suitable design of blended learning that can catch the attention of students (21). Besides that, another study in the United States showed the challenges in designing the assessment and grading in blended learning. However, blended learning does increase the interest and participation of the students in class during face-to-face lectures (22). Furthermore, a study in Malaysia indicated that the problems arising from blended learning concerned the speed of the internet connection and many assignments to be done online (19). In order to make blended learning is successful in the learning curriculum it must be attractive, easy to use and adding chat box (23).

There are many advantages and disadvantages in using blended learning. Most of blended learning succeeds in motivating students to participate actively in class and achieve a good academic performance. However, students tend to spend a long period of time on the internet to do a task and download the notes. This may cause them to be less socially involved with the people around them. The student must develop a good time management to achieve a study-life balance in the university in order to become involved with other activities.

\section{CONCLUSION}

Blended learning has been stated to increase students' commitment and perseverance in learning activities and class attendance. Students had moderate preferences with regard to perception, attitudes and concepts. Students have a more positive attitude towards blended learning as it enhances and supports the learning process with low levels of negative impression. There were no differences in the years of study and the departments to blended learning among biomedical and nutrition students. Implementing blended learning is recommended in order to motivate students to learn at their own pace.

\section{REFERENCES}

1. Garrison R. Implications of online learning for the conceptual development and practice of distance education. Journal of Distance Education. 2009;23(2):93-103.

2. Ginns P, Ellis R. Quality in blended learning: exploring the relationships between on-line and face-to-face teaching and learning. The Internet and Higher Education. 2007;10(1):53-64. https://doi. org/10.1016/j.iheduc.2006.10.003

3. Azizan FZ. Blended learning in higher education institution in Malaysia. Proceedings of regional conference on knowledge integration in ICT 2010. 1-2 June 2010. Kolej Universiti Islam Antarabangsa. p. 454-66.

4. Hsu LL. Blended learning in ethics education: a survey of nursing students. Nursing Ethics. 2011;18(3):418-30. https://doi.org/10.1177/0969733011398097

5. Kiviniemi MT. Effects of a blended learning approach on student outcomes in a graduate-level public health course. BMC Medical Education. 2014;14(1):47. https://doi.org/10.1186/1472-6920-14-47

6. Roslina AT, Nur Shaminah MK, SianHoon T. Students' satisfaction on blended learning: a preliminary study. Pertanika Journal of Social Sciences \& Humanities. 2013;21(3):1119-31.

7. Tan $\mathrm{M}, \mathrm{Hew} \mathrm{KF}$. Incorporating meaningful gamification in a blended learning research methods class: examining student learning, engagement, and affective outcomes. Australasian Journal of Educational Technology. 2016;32(5):19-34. https://doi. org/10.14742/ajet.2232 
8. Al-Qahtani AA, Higgins SE. Effects of traditional, blended and e-learning on students' achievement in higher education. Journal of Computer Assisted Learning. 2013;29(3):220-34. https://doi.org/10.1111/ j.1365-2729.2012.00490.x

9. Gaebel M, Kupriyanova V, Morais R, Colucci E. E-learning in European higher education institutions: results of a mapping survey conducted in October-December 2013. Belgium: European University Association; 2014.

10. Ja'ashan MM. Perceptions and attitudes towards blended learning for English courses: a case study of students at University of Bisha. English Language Teaching. 2015;8(9):40-50. https://doi. org/10.5539/elt.v8n9p40

11. Tselios N, Daskalakis S, Papadopoulou M. Assessing the acceptance of a blended learning university course. Journal of Educational Technology \& Society. $2011 ; 14(2): 224-35$.

12. López-Pérez MV, Pérez-López MC, Rodríguez-Ariza L. Blended learning in higher education: students' perceptions and their relation to outcomes. Computers \& Education. 2011;56(3):818-26. https://doi. org/10.1016/j.compedu.2010.10.023

13. Al Zumor AW, Al Refaai IK, Eddin EA, AlRahman FH. EFL students' perceptions of a blended learning environment: advantages, limitations and suggestions for improvement. English Language Teaching. 2013;6(10):95110. https://doi.org/10.5539/elt.v6n10p95

14. Majid NA. Integration of Web 2.0 tools in learning a programming course. TOJET: Turkish Online Journal of Educational Technology. 2014;13(4):88-94.
15. Rosli Y, Ishak I, Saat ZM. The effectiveness of blended learning approach in redesigned anatomy curriculum for the Faculty of Health Science undergraduates Universiti Kebangsaan Malaysia. Advanced Science Letters. 2017;23(2):1197-200. https://doi. org/10.1166/asl.2017.7537

16. Sanchez-Gordon S, Luján-Mora S. Accessible blended learning for non-native speakers using MOOCs. 2015 International Conference on Interactive Collaborative and Blended Learning (ICBL); 9-11 December 2015. Mexico City: Technologico de Monterrey; p. 19-24. https://doi. org/10.1109/ICBL.2015.7387645

17. O’Connor C, Mortimer D, Bond S. Blended learning: issues, benefits and challenges. International Journal of Employment Studies. 2011;19(2):63.

18. Mohamad M, Hussin H, Shaharuddin S. Adult learners' perceptions of designed hypermedia in a blended learning course at a public university in Malaysia. TOJET: Turkish Online Journal of Educational Technology. 2015;14(1):31-8.

19. Kukulska-Hulme A, Pettit J, Bradley L, Carvalho AA, Herrington A, Kennedy $\mathrm{DM}$, et al. Mature students using mobile devices in life and learning. International Journal of Mobile and Blended Learning. 2011;3(1):18-52. https://doi.org/10.4018/ jmbl.2011010102

20. Thang SM, Wong FF, Noor NM, Mustaffa $\mathrm{R}$, Mahmud N, Ismail $\mathrm{K}$. Using a blended approach to teach English for academic purposes: Malaysian students' perceptions of redesigned course materials. International Journal of Pedagogies and Learning. 2012;7(2):142-53.

21. Alebaikan R, Troudi S. Blended learning in Saudi universities: challenges and perspectives. ALT-J. 2010;18(1):49-59. https://doi.org/10.1080/09687761003657614 
22. Kenney J, Newcombe E. Adopting a blended learning approach: challenges encountered and lessons learned in an action research study. Journal of Asynchronous Learning Networks. 2011;15(1):45-57. https://doi. org/10.24059/olj.v15i1.182
23. Saat NZ, Chong PN, Omar B, Manaf Z, Ishak I, Ramli N, et al. Knowledge, perception and practice on the usage of e-learning among health students in Kuala Lumpur. Procedia - Social and Behavioral Sciences. 2012;60:610-14. https://doi. org/10.1016/j.sbspro.2012.09.430 